\title{
The Effect of Adrenalectomy on Exercise Response of the Renin- Angiotensin-Aldosterone System and Exercise Tolerance in Primary Aldosteronism
}

\author{
V. TUKA ${ }^{1}$, M. MATOULEK ${ }^{1}, J_{.}$ROSA $^{2}$, O. PETRÁK ${ }^{2}$, O. MIKE $\check{S}^{1}$, Z. KRÁTKÁ $^{2}$, \\ B. ŠTRAUCH ${ }^{2}$, R. HOLAJ ${ }^{2}$, T. ZELINKA ${ }^{2 *}$, J. WIDIMSKÝ $^{2} *$ \\ *These authors contributed equally to this work. \\ ${ }^{1}$ Centre of Cardiovascular Rehabilitation, Third Department of Medicine - Department of \\ Endocrinology and Metabolism of the First Faculty of Medicine, Charles University and General \\ University Hospital in Prague, Czech Republic, ${ }^{2}$ Centre for Hypertension, Third Medical \\ Department - Department of Endocrinology and Metabolism of the First Faculty of Medicine, \\ Charles University and General University Hospital, Prague, Czech Republic
}

Received April 13, 2017

Accepted September 21, 2017

On-line January 5, 2018

\begin{abstract}
Summary
Primary aldosteronism (PA) is associated with objectively measured lower physical fitness and blunted response of the renin-angiotensin-aldosterone system to exercise. The purpose of this pilot study was to objectively measure exercise response of the renin-angiotensin-aldosterone system and cardiopulmonary fitness changes after laparoscopic adrenalectomy (ADE) in patients with unilateral PA. We examined a total of 14 patients with confirmed $P A$ before and after $A D E$, by means of spiroergometry and hormonal evaluation. As expected, after adrenalectomy basal aldosterone (Aldo) levels before exercise decreased significantly, with a concomitant increase in plasma renin (PR). The increase in Aldo $(285.9 \pm 171.3$ to $434.1 \pm$ $278.2 \mathrm{ng} / \mathrm{l} ; \mathrm{p}=0.02)$ and blunted increase in PR (7.1 \pm 0.4 to $8.9 \pm 10.4 \mathrm{pg} / \mathrm{ml} ; \mathrm{NS})$ post-exercise before $\mathrm{ADE}$ became significant after ADE Aldo post-ADE $(46.8 \pm 18.8$ to $106.5 \pm$ $68.1 \mathrm{ng} / \mathrm{l} ; \mathrm{p}<0.0001)$ and PR post-ADE $(20.1 \pm 14.5$ to $33.9 \pm$ $30.7 \mathrm{pg} / \mathrm{ml} ; \mathrm{p}=0.014)$. After adrenalectomy, the patients had a non-significant increase in peak workload and $\mathrm{VO}_{2 \text { peak }}$. We found normalization of the renin-angiotensin-aldosterone system response to exercise with little changes in cardiopulmonary fitness six months after ADE.
\end{abstract}

\section{Key words}

Primary hyperaldosteronism • Unilateral adrenalectomy • Physical fitness $\bullet$ Exercise blood pressure $\bullet$ Exercise stress test

\section{Corresponding author}

V. Tuka, Third Department of Internal Medicine, General University Hospital in Prague, U Nemocnice 1, Prague 2, 128 08, Czech Republic. Fax: +420 224919780 . E-mail: Vladimir.Tuka@vfn.cz

\section{Introduction}

Primary aldosteronism (PA) is the most common form of secondary hypertension affecting at least $4 \%$ of patients with moderate to severe hypertension (Funder et al. 2016). Low levels of serum potassium are found in the majority of patients with PA (Somloova et al. 2016). Hypokalemia influences muscle function, which leads to easy fatigability and muscle weakness (Gennari 1998). Patients with PA also have lower quality of life, especially in the domains of physical functioning, vitality, and general health (Sukor et al. 2010). PA is associated with objectively measured lower physical fitness, which is inversely dependent on kalemia and the severity of hypertension. Furthermore, the response of the renin-angiotensin-aldosterone system is blunted during maximal exercise (Tuka et al. 2017).

Unilateral adrenalectomy (ADE) is the therapy of choice in patients with PA with unilateral aldosterone overproduction (Stowasser 2014). After ADE, many 
patients are cured of hypertension and the remaining have a significant decrease in antihypertensive medication (Letavernier et al. 2008, Stowasser 2014). Furthermore, already three months post-surgery, their quality of life (in both physical and psychological domains) improves, approaching that of the general population (Sukor et al. 2010).

The purpose of this pilot study was to objectively measure exercise response of the reninangiotensin-aldosterone system and cardiopulmonary fitness changes after laparoscopic adrenalectomy in patients with unilateral PA. We hypothesized that ADE through hormonal and potassium level normalization and blood pressure (BP) decrease will lead to improved physical fitness.

\section{Patients and Methods}

\section{Study population}

We examined a total of 18 patients with confirmed PA, who were indicated for ADE after adrenal vein sampling performed between May 2013 and October 2014. All patients were scheduled for a cardiopulmonary exercise stress test (CPX) and ambulatory blood pressure monitoring after adrenal vein sampling (Pre-ADE) and 6 months after ADE (Post-ADE). Of the 18 patients who underwent ADE, 15 arrived for the second CPX. In one patient, significant post-exercise hypotension occurred and was excluded from analysis. Data from the remaining 14 patients were analyzed. Four patients were treated with dyslipidemia, one patient had Type 2 diabetes and two patients were on stable ( $>6$ months) substitution therapy for hypothyroidism. There was only one current smoker in our population; seven patients had been ex-smokers for more than ten years before taking part in this study. The patients were advised not to exercise for the first four to six weeks after ADE. Thereafter, they were advised to resume their normal daily activities without special advice on physical activity.

All patients gave informed consent. The study was approved by the local Ethical Committee (2/13 GRANT) and was conducted in accordance with the Declaration of Helsinki.

The diagnosis of PA was made in the Centre for the Diagnosis and Treatment of Arterial Hypertension, in accordance with the current guidelines on the diagnosis and treatment of PA (low plasma renin, high aldosterone, high aldosterone/renin ratio, non-supressibility of aldosterone production during saline infusion loading tests) (Funder et al. 2016, Somloova et al. 2016). The only allowed antihypertensive medication at study entry was verapamil and doxazosin at least 2-3 weeks before the study. Oral potassium supplementation was given, if needed, aiming to correct hypokalemia before all examinations.

\section{Cardiopulmonary exercise stress test}

Exercise stress tests were carried out on a cycle ergometer (Ergoline e-bike, GE Medical Systems, Milwaukee, USA) with a combined protocol, with two consecutive 3 -min constant load steps $(0.5 \mathrm{~W} / \mathrm{kg}$ and $1.0 \mathrm{~W} / \mathrm{kg}$ ), followed by a ramped increase in work intensity. During the CPX, the following parameters were measured at each step as described in our previous publication (Tuka et al. 2017): workload (W), systolic blood pressure - SBP ( $\mathrm{mm} \mathrm{Hg}$ ), diastolic blood pressure - DBP (mm Hg), heart rate - HR (beat per minute bpm), oxygen consumption $-\mathrm{VO}_{2}(\mathrm{ml} / \mathrm{kg} / \mathrm{min})$, carbon dioxide output $-\mathrm{VCO}_{2}(\mathrm{ml} / \mathrm{min})$, and rating of perceived exertion - RPE according to Borg (1974). The lower case ${ }_{0}$ marks baseline data; $0.5,1.0$ and peak data at work rate of $0.5 \mathrm{~W} / \mathrm{kg}, 1.0 \mathrm{~W} / \mathrm{kg}$ and peak workload, respectively.

\section{Laboratory analysis}

A blood sample was taken before the CPX and after recovery, i.e. approximately 5-7 $\mathrm{min}$ after peak exercise. Plasma renin (PR) and aldosterone (Aldo) were measured by radioimmunoanalysis, using commercially available kits (Immunotech; Beckman Coulter Company, Prague, Czech Republic). Serum cortisol levels were measured, using the competitive chemiluminiscent immunoassay (ADVIA: Centaur Siemens, Erlangen, Federal Republic of Germany). Interassay coefficient of variability was $9.5 \%$.

\section{Ambulatory blood pressure monitoring}

Twenty-four-hour ambulatory BP monitoring (ABPM) was performed, using an oscillometric device (SpaceLabs 90207 or 90217; SpaceLabs Medical, Redmond, Washington, USA), which was set to measure every 20 min during the day (from 06:00 to 22:00 h) and every $30 \mathrm{~min}$ during the night (from 22:00 to $06: 00 \mathrm{~h}$ ). The following parameters were measured: SBP, DBP, HR and their standard deviations during the whole period and during the daytime and night-time periods. The suffixes ${ }_{24, \text { day }}$ and ${ }_{\text {night }}$ were used respectively. 
Statistics

All calculations were performed using StatSoft, Inc. (2013). STATISTICA (data analysis software system), version 12. Continuous variables were expressed as mean $\pm \mathrm{SD}$. The hormonal changes were tested, using Student's paired t-test. The differences between data Pre-ADE and Post-ADE were tested, using Student's paired t-test. The level of significance was set at $\mathrm{p}<0.05$.

\section{Results}

After ADE, 10 patients did not use any antihypertensive drugs, three patients still used verapamil at a dose of $240 \mathrm{mg}$ once daily (one with concomitant use of telmisartan $80 \mathrm{mg}$ once daily), and one patient still used doxazosin $4 \mathrm{mg}$ daily with concomitant use of perindopril $4 \mathrm{mg}$ once daily. After ADE, no patient required potassium supplementation and all had normal kalemia (Table 1). As expected, blood pressures dropped. The blood pressures obtained during ABPM are summarized in Table 2 .

As expected, after ADE basal Aldo before exercise decreased significantly with a concomitant increase in PR. The blunted increase in both Aldo and PR post-exercise before ADE became significant after ADE (Table 3).

Table 1. Study population characteristics before and 6 months after adrenalectomy.

\begin{tabular}{lccc}
\hline & Pre-ADE & Post-ADE & p-value \\
\hline No. patients & 14 & 14 & \\
Male/female & $7 / 7$ & N/A & N/A S \\
Age (years) & $48 \pm 10$ & $88.9 \pm 23.5$ & NS \\
Weight $(k g)$ & $90.9 \pm 27.0$ & $104 \pm 17$ & NS \\
Waist circumference (cm) & $104 \pm 16$ & $29.3 \pm 4.9$ & 0.008 \\
BMI & $29.7 \pm 5.6$ & 3 & 0.0018 \\
No. patients on verapamil & 14 & 1 & 0.000094 \\
No. patients on doxazosin & 14 & 0 & 0.000021 \\
Kalium chloratum dose (g) & $5.7 \pm 3.9$ & $4.5 \pm 0.2$ & \\
Kalemia (mmol/l) & $3.7 \pm 0.4$ & & \\
\hline
\end{tabular}

Pre-ADE - before adrenalectomy, Post-ADE - 6 months after adrenalectomy, NS - non-significant.

Table 2. Ambulatory blood pressure monitoring data before and 6 months after adrenalectomy.

\begin{tabular}{|c|c|c|c|c|}
\hline & & Pre-ADE & Post-ADE & p-value \\
\hline \multirow[t]{3}{*}{ All day } & $S B P(m m ~ H g)$ & $145 \pm 9$ & $128 \pm 11$ & 0.002 \\
\hline & $D B P(m m ~ H g)$ & $90 \pm 7$ & $81 \pm 9$ & 0.026 \\
\hline & $H R(b p m)$ & $64 \pm 9$ & $70 \pm 9$ & 0.13 \\
\hline \multirow[t]{3}{*}{ Day time } & $S B P(m m ~ H g)$ & $149 \pm 11$ & $131 \pm 11$ & 0.004 \\
\hline & $\mathrm{DBP}(\mathrm{mm} \mathrm{Hg})$ & $93 \pm 6$ & $84 \pm 9$ & 0.03 \\
\hline & $H R(b p m)$ & $67 \pm 9$ & $73 \pm 11$ & 0.08 \\
\hline \multirow[t]{3}{*}{ Night time } & $S B P(m m ~ H g)$ & $134 \pm 7$ & $120 \pm 11$ & 0.003 \\
\hline & $D B P(m m H g)$ & $83 \pm 7$ & $74 \pm 10$ & 0.03 \\
\hline & $H R(b p m)$ & $58 \pm 9$ & $62 \pm 7$ & 0.22 \\
\hline
\end{tabular}

Pre-ADE - before adrenalectomy, Post-ADE - 6 months after adrenalectomy. 
Table 3. Hormonal changes before and after cardiopulmonary exercise testing before and 6 months after adrenalectomy.

\begin{tabular}{|c|c|c|c|c|}
\hline & & Pre-CPX & Post-CPX & $\begin{array}{c}\text { p-value } \\
\text { Pre-CPX vs. post-CPX }\end{array}$ \\
\hline \multirow[t]{2}{*}{$P R(p g / m l)$} & Pre-ADE & $7.1 \pm 0.4$ & $8.9 \pm 10.4$ & NS \\
\hline & Post-ADE & $20.1 \pm 14.5^{* *}$ & $33.9 \pm 30.7^{* *}$ & 0.014 \\
\hline \multirow[t]{2}{*}{ Aldo $(n g / l)$} & Pre-ADE & $285.9 \pm 171.3$ & $434.1 \pm 278.2$ & 0.02 \\
\hline & Post-ADE & $46.8 \pm 18.8 * * *$ & $106.5 \pm 68.1^{* *}$ & $<0.0001$ \\
\hline \multirow[t]{2}{*}{ Aldo/PR (ng/dl) } & Pre-ADE & $9.9 \pm 11.8$ & $10.9 \pm 12.7$ & NS \\
\hline & Post-ADE & $0.3 \pm 0.2^{*}$ & $0.5 \pm 0.4^{*}$ & 0.001 \\
\hline \multirow[t]{2}{*}{ Cortisol (nmol/l) } & Pre-ADE & $329 \pm 93$ & $507 \pm 74$ & 0.03 \\
\hline & Post-ADE & $366 \pm 53$ & $474 \pm 89$ & $<0.001$ \\
\hline
\end{tabular}

PR - plasma renin, Aldo - plasma aldosterone, CPX - cardiopulmonary exercise test, Pre-ADE - before adrenalectomy, Post-ADE 6 months after adrenalectomy, NS - non-significant. * $p<0.05, * * p<0.01, * * * p<0.001$ comparing Pre-ADE and Post-ADE.

Table 4. Cardiopulmonary exercise stress test data before and 6 months after adrenalectomy.

\begin{tabular}{|c|c|c|c|c|c|c|c|c|}
\hline & & \multirow{2}{*}{ Baseline } & \multicolumn{3}{|c|}{ Exercise } & \multicolumn{3}{|c|}{ Recovery } \\
\hline & & & $0.5 \mathrm{~W} / \mathrm{kg}$ & $1.0 \mathrm{~W} / \mathrm{kg}$ & Peak & $1 \mathrm{~min}$ & $3 \mathrm{~min}$ & $5 \mathrm{~min}$ \\
\hline \multirow[t]{2}{*}{ Workload $(W)$} & Pre-ADE & N/A & $45 \pm 14$ & $90 \pm 27$ & $189 \pm 57$ & $\mathrm{~N} / \mathrm{A}$ & $\mathrm{N} / \mathrm{A}$ & N/A \\
\hline & Post-ADE & N/A & $44 \pm 11$ & $88 \pm 24$ & $200 \pm 54$ & N/A & N/A & N/A \\
\hline \multirow[t]{2}{*}{$\mathrm{SBP}(\mathrm{mm} \mathrm{Hg})$} & Pre-ADE & $138 \pm 21$ & $148 \pm 23$ & $170 \pm 23$ & $192 \pm 27$ & $172 \pm 38$ & $154 \pm 34$ & $135 \pm 27$ \\
\hline & Post-ADE & $132 \pm 13$ & $146 \pm 17$ & $164 \pm 24$ & $197 \pm 34$ & $173 \pm 35$ & $153 \pm 27$ & $131 \pm 17$ \\
\hline \multirow[t]{2}{*}{$D B P(m m H g)$} & Pre-ADE & $86 \pm 10$ & $88 \pm 12$ & $91 \pm 10$ & $96 \pm 13$ & $82 \pm 15$ & $76 \pm 13$ & $76 \pm 12$ \\
\hline & Post-ADE & $87 \pm 7$ & $92 \pm 7$ & $94 \pm 7$ & $105 \pm 9$ & $91 \pm 9$ & $87 \pm 5^{*}$ & $85 \pm 7$ \\
\hline \multirow[t]{2}{*}{$H R(b p m)$} & Pre-ADE & $81 \pm 14$ & $101 \pm 13$ & $124 \pm 19$ & $151 \pm 24$ & $126 \pm 23$ & $98 \pm 16$ & $93 \pm 16$ \\
\hline & Post-ADE & $87 \pm 18^{*}$ & $108 \pm 16$ & $129 \pm 20$ & $166 \pm 14 * * *$ & $141 \pm 14 * *$ & $110 \pm 18 * * *$ & $99 \pm 18$ \\
\hline \multirow[t]{2}{*}{$\mathrm{VO}_{2}(\mathrm{ml} / \mathrm{kg} / \mathrm{min})$} & Pre-ADE & $\mathrm{N} / \mathrm{A}$ & $11.9 \pm 0.9$ & $18.5 \pm 1.1$ & $27.7 \pm 4.8$ & $\mathrm{~N} / \mathrm{A}$ & N/A & N/A \\
\hline & Post-ADE & $\mathrm{N} / \mathrm{A}$ & $11.8 \pm 1.6$ & $17.4 \pm 1.9$ & $29.0 \pm 5.3$ & $\mathrm{~N} / \mathrm{A}$ & $\mathrm{N} / \mathrm{A}$ & N/A \\
\hline \multirow[t]{2}{*}{$R P E$} & Pre-ADE & $\mathrm{N} / \mathrm{A}$ & $8.3 \pm 1.4$ & $12.5 \pm 1.2$ & $16.1 \pm 1.4$ & $\mathrm{~N} / \mathrm{A}$ & $\mathrm{N} / \mathrm{A}$ & N/A \\
\hline & Post-ADE & N/A & $8.5 \pm 1.8$ & $12.1 \pm 1.2$ & $16.4 \pm 2.1$ & N/A & N/A & N/A \\
\hline
\end{tabular}

$\mathrm{SBP}$ - systolic blood pressure, DBP - diastolic blood pressure, $\mathrm{HR}$ - heart rate, $\mathrm{VO}_{2}$ - oxygen consumption, METs - metabolic equivalent of task, RER - respiratory exchange ratio, RPE - rating of perceived exertion according to Borg, Pre-ADE - before adrenalectomy, Post-ADE -6 months after adrenalectomy. N/A, not applicable. $* p<0.05, * * p<0.01, * * * p<0.001$.

After ADE, the patients had a non-significant increase in peak workload and $\mathrm{VO}_{2 \text { peak }}$. The $\mathrm{VO}_{2 \text { peak }} \mathrm{SD}$ increased non-significantly $(-0.78 \pm 1.1 \quad$ vs. $-0.68 \pm 1.3$ $\mathrm{ml} / \mathrm{kg} / \mathrm{min}, \mathrm{p}=0.8)$ and $\mathrm{VO}_{2 \text { peak }} \%$ also increased nonsignificantly ( $89 \pm 15$ vs. $91 \pm 17 \%, \mathrm{p}=0.7)$. The length of the test was non-significantly longer after ADE
(9:04 $\pm 1: 08$ vs. 9:30 $\pm 1: 18 \mathrm{~min}, \mathrm{p}=0.2$ ). The biggest changes, although non-significant, were observed in younger patients (Fig. 1). We observed significantly higher heart rate at baseline, peak exercise and recovery period after ADE. The hemodynamic response during CPX is summarized in Table 4. 


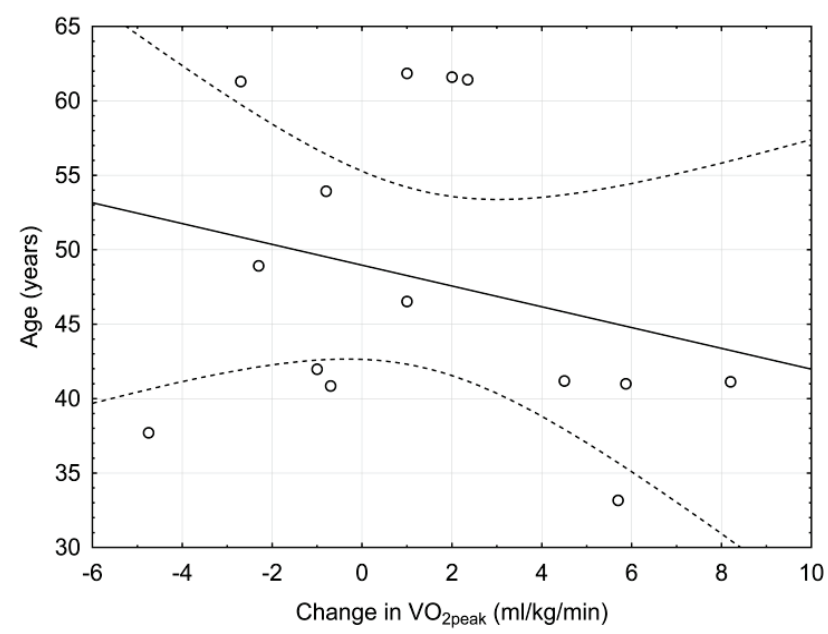

Fig. 1. The correlation of the change in peak oxygen consumption $\left(\mathrm{VO}_{2 \text { peak }}\right)$ and patients' age.

\section{Discussion}

To our knowledge, this is the first study dealing with changes of cardiopulmonary fitness induced by therapy of PA (unilateral ADE in patients with PA). We observed normalization of the renin-angiotensinaldosterone system, kalemia and BP decrease. Cardiopulmonary fitness increased only non-significantly and mostly in younger patients.

Before ADE, Aldo increased significantly, but from elevated basal values after dynamic exercise, whereas the basally suppressed PR did not increase significantly. After ADE, Aldo and PR increased from normal basal values, as would be expected in healthy untrained men and women (Kinugawa et al. 1997, Borer 2013). This shows a restitution of normal functioning of the renin-angiotensin-aldosterone system during exercise.

As observed earlier, the quality of life in all domains, also encompassing physical performance, improves as early as 3 months after ADE (Sukor et al. 2010). In our cohort, the cardiopulmonary fitness parameters did not increase significantly at 6 months, but there was a trend of longer test duration after ADE. There could be several reasons. The 6 months are too short a period of time to improve the long influence of aldosterone and hypokalemia on skeletal muscles. Furthermore, after ADE patients are advised not to exercise for the first four to six weeks. On the other hand, after exercise training, changes in cardiopulmonary fitness parameters can be observed as early as 3 months after initiation of training (McArdle et al. 2010).

The physical performance and easy fatigability in patients with PA could rather be linked to muscular endurance than acute cardiovascular performance. This could explain the improvement of quality of life in the study by Sukor et al. (2010) and non-significant changes in the cardiopulmonary exercise test. A more sensitive test could be the use of a test with pre-set (75-80\% $\left.\mathrm{VO}_{2 \text { peak }}\right)$ continuous submaximal intensity and a comparison of endurance time of the exercise patients would perform (Palange et al. 2007). This approach was shown to be superior in e.g. patients with chronic obstructive pulmonary disease after oxitropium bromide initiation, where traditional measures of exercise performance (maximal workload, $\mathrm{VO}_{2 \max }$ ) increased by only $5 \%$, whereas endurance time increased by $19 \%$ (Oga et al. 2000).

The final possibility is the size of the cohort which is relatively small, which could affect the potential to produce statistically significant changes in $\mathrm{VO}_{2 \text { peak }}$. This explanation is less probable, because half of the patients in the cohort improved and half decreased their $\mathrm{VO}_{2 \text { peak }}$.

A potential confounder in our cohort is the use of verapamil during the exercise test pre-ADE in most patients, and its use only by three patients in the exercise test post-ADE, which explains the higher HR post-ADE. Verapamil was shown to improve left ventricular filling pressures and to improve exercise performance in elderly hypertensive and normotensive individuals (Petrella et al. 1994). This could be partially explained by reduced ventriculo-vascular stiffening. After verapamil intravenous injection, elderly volunteers performed better than after saline injection. After verapamil, exercise duration before anaerobic threshold and total exercise duration increased without no change in $\mathrm{VO}_{2 \max }$ (Chen et al. 1999).

The strength of the study is the uniform cohort of patients with the objectively established diagnosis of unilaterality of PA in whom ADE led to a significant decrease of BP and normalization of hypokalemia. On the other hand, the limitation of the study is the lack of a control group.

In conclusion, we found normalization of the renin-angiotensin-aldosterone system response to exercise with little changes in cardiopulmonary fitness six months after ADE. For future investigations of cardiopulmonary fitness in patients with PA, endurance tests with a concomitant quality of life measurement would be more appropriate. Future research should also study the effect of medical therapy of PA on cardiopulmonary fitness and the effect of exercise prescription. 


\section{Conflict of Interest}

There is no conflict of interest.

\section{Acknowledgements}

This work was supported by a research grant from the Czech Society of Cardiology and by Charles University research projects [PRVOUK P25/LF1/2].

\section{References}

BORER KT: Advanced Exercise Endocrinology. Human Kinetics, Champaign, 2013.

BORG GA: Perceived exertion. Exerc Sport Sci Rev 2: 131-153, 1974.

CHEN CH, NAKAYAMA M, TALBOT M, NEVO E, FETICS B, GERSTENBLITH G, BECKER LC, KASS DA: Verapamil acutely reduces ventricular-vascular stiffening and improves aerobic exercise performance in elderly individuals. J Am Coll Cardiol 33: 1602-1609, 1999.

FUNDER JW, CAREY RM, MANTERO F, MURAD MH, REINCKE M, SHIBATA H, STOWASSER M, YOUNG WF JR: The management of primary aldosteronism: case detection, diagnosis, and treatment: an Endocrine Society Clinical Practice Guideline. J Clin Endocrinol Metab 101: 1889-1916, 2016.

GENNARI FJ: Hypokalemia. $N$ Engl J Med 339: 451-458, 1998.

KINUGAWA T, OGINO K, MIYAKODA H, SAITOH M, HISATOME I, FUJIMOTO Y, YOSHIDA A, SHIGEMASA C, SATO R: Responses of catecholamines, renin-angiotensin system, and atrial natriuretic peptide to exercise in untrained men and women. Gen Pharmacol 28: 225-228, 1997.

LETAVERNIER E, PEYRARD S, AMAR L, ZINZINDOHOUE F, FIQUET B, PLOUIN PF: Blood pressure outcome of adrenalectomy in patients with primary hyperaldosteronism with or without unilateral adenoma. J Hypertens 26: 1816-1823, 2008.

MCARDLE WD, KATCH FI, KATCH VL: Exercise Physiology. Lippincott Williams and Wilkins, Baltimore, 2010.

OGA T, NISHIMURA K, TSUKINO M, HAJIRO T, IKEDA A, IZUMI T: The effects of oxitropium bromide on exercise performance in patients with stable chronic obstructive pulmonary disease. A comparison of three different exercise tests. Am J Respir Crit Care Med 161: 1897-1901, 2000.

PALANGE P, WARD SA, CARLSEN KH, CASABURI R, GALLAGHER CG, GOSSELINK R, O'DONNELL DE, PUENTE-MAESTU L, SCHOLS AM, SINGH S, WHIPP BJ: Recommendations on the use of exercise testing in clinical practice. Eur Respir J 29: 185-209, 2007.

PETRELLA RJ, NICHOL PM, CUNNINGHAM DA, PATERSON DH: Verapamil improves left ventricular filling and exercise performance in hypertensive and normotensive elderly individuals. Can J Cardiol 10: 973-981, 1994.

SOMLOOVA Z, PETRAK O, ROSA J, STRAUCH B, INDRA T, ZELINKA T, HALUZIK M, ZIKAN V, HOLAJ R, WIDIMSKY J JR: Inflammatory markers in primary aldosteronism. Physiol Res 65: 229-237, 2016.

STOWASSER M: Aldosterone excess and resistant hypertension: investigation and treatment. Curr Hypertens Rep 16: 439, 2014.

SUKOR N, KOGOVSEK C, GORDON RD, ROBSON D, STOWASSER M: Improved quality of life, blood pressure, and biochemical status following laparoscopic adrenalectomy for unilateral primary aldosteronism. $J$ Clin Endocrinol Metab 95: 1360-1364, 2010.

TUKA V, MATOULEK M, ZELINKA T, ROSA J, PETRAK O, MIKES O, KRATKA Z, STRAUCH B, HOLAJ R, WIDIMSKY J JR: Lower physical fitness in patients with primary aldosteronism is linked to the severity of hypertension and kalemia. Physiol Res 66: 41-48, 2017. 